\title{
Effect of plaque accumulation and occlusal overload on peri-implant bone loss
}

\author{
Elena Dellepiane, Maria Menini, Paolo Canepa, Paolo Pera \\ Department of Implant and Prosthetic Dentistry, University of Genoa, Genoa, Italy
}

\begin{abstract}
This paper presents a case report where the influence of plaque accumulation and overload on a dental implant was observed. The patient presented crown loss on one implant affected by peri-implant bone resorption and gingival inflammation associated with poor oral hygiene. After 12 months a single crown was delivered, but as soon as the occlusal load was applied bone loss and implant failure occurred. In the present case report the dental implant remained stable as long as the implant was not loaded, although a $100 \%$ plaque index and bleeding on probing were present during the entire followup period. In contrast, as soon as an occlusal load was applied periimplant bone loss and implant failure occurred. These observations suggest that plaque accumulation alone is not a triggering factor for peri-implant bone loss and implant failure. On the contrary, occlusal load, when not properly controlled, might cause bone resorption.
\end{abstract}

\section{Introduction}

In recent years several studies investigated the etiology of periimplant disease, the so-called peri-implantitis. ${ }^{1}$ Triggering factors

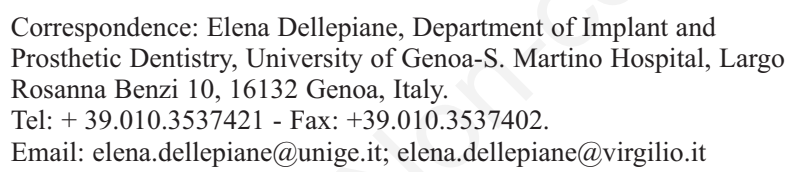

Key words: Bone resorption; Dental implants; Implant failure; Occlusal overload; Plaque.

Received for publication: 30 July 2016.

Revision received: 2 August 2016.

Accepted for publication: 20 January 2017.

CC Copyright E. Dellepiane et al., 2017

Licensee PAGEPress, Italy

Journal of Biological Research 2017; 90:6212

doi:10.4081/jbr.2017.6212

This article is distributed under the terms of the Creative Commons Attribution Noncommercial License (by-nc 4.0) which permits any noncommercial use, distribution, and reproduction in any medium, provided the original author(s) and source are credited. for peri-implant bone loss and implant failure are generally gathered under two main categories: biological factors (e.g., presence of an aggressive bacterial strain) and biomechanical factors (e.g., excessive mechanical stress). ${ }^{2}$ Plenty of papers focused on these two claimed etiological factors of peri-implant disease, and most of them are animal studies. ${ }^{1}$ Dealing with animal studies, it is evident that the literature is not unanimous about peri-implantitis etiology. In fact, studies on a dog model $^{3}$ suggested a plaque related etiology. On the contrary, the studies on the monkey model ${ }^{4}$ show an overloading etiology or a synergism between plaque accumulation and overloading. The different study design and the different animal model could account for this inconsistency. Moreover, data on animal studies should be used with caution when discussing clinical evidence. In particular, the use of ligatures, in order to induce plaque accumulation on dental implants in animal models, results in a foreign body reaction and induce a destructive process around implants that do not represent clinical reality. 5

Bone has been demonstrated to be sensitive to loading conditions ${ }^{6}$ and several authors consider occlusal load a critical factor influencing the dental implant healing phase and the long-term survival and success of dental implants. ${ }^{7,8}$ Nagasawa et al. ${ }^{9}$ revealed the possibility of bone loss around overloaded implants in the absence of infection using a rat model. These results agree with previous studies realized on monkeys. ${ }^{4}$ On the other hand, some animal studies on $\operatorname{dogs}^{3}$ described overloading as a cofactor in the etiology of peri-implant disease, underlining how in the presence of peri-implant mucosal health, excessive occlusal load on titanium implants did not result in loss of osseointegration or marginal bone loss. In contrast, overloading aggravated the plaque-induced bone resorption when peri-implant inflammation was present. This is confirmed in systematic reviews of animal studies. ${ }^{10}$

As described above, animal studies are not unanimous about peri-implantitis etiology.

Moreover these data should be subjected to careful interpretation when reliable clinical evidence is absent. Overloading research designs used in the animal model do not adequately simulate the human situation. The majority of patients are extremely sensitive to even minute occlusal imperfections in occlusion on implant-supported restorations and would demand an immediate corrective action by the dentist. Moreover, the above-mentioned papers are difficult to compare because of differences in study design. ${ }^{1}$

A recent systematic review ${ }^{11}$ of clinical human studies suggested that occlusal overload is positively associated with periimplant marginal bone loss.

In clinical studies, bruxism or parafunctions were often used as situations where overloading can be manifested and was reported to cause failures. ${ }^{12}$ However, a more precise definition of occlusal overload would be required to investigate its role in periimplant disease.

Some case reports supported the role of overloading in implant failure. ${ }^{13}$ In absence of systematic evidence from human 
studies, data from case reports might contribute to understand the role of the possible factors influencing the loss of osseointegration of successfully integrated dental implants.

Some clinical studies found that poor oral hygiene is a risk factor for peri-implant disease. ${ }^{14}$ These results are in conflict with a split-mouth study ${ }^{15}$ which showed that, even though acid-etched titanium surfaces retain more plaque than machined ones, this does not negatively affect peri-implant bone loss and peri-implant soft tissue health.

Up to now, animal studies and clinical trials are not able to identify the etiology of peri-implant bone loss and implant failure. The etiological factors and the definition itself of peri-implantitis are discussion topics. ${ }^{1}$

The present paper describes a clinical case where the effect of plaque accumulation and occlusal overload on peri-implant bone loss and implant failure were observed throughout a 2-year period.

\section{Case Report}

A 43-year-old male patient came for consultation at the Department of Fixed and Implant Prosthodontics of the University of Genoa on the $21^{\text {st }}$ December 2011 because of pain caused by pulpitis of the teeth 35 and 37 . The patient reported a good general health except that he suffered from hiatus hernia and he was in therapy with pantoprazole and calcium carbonate $\left(\right.$ Gaviscon ${ }^{\circledR}$; Reckitt Benckiser Group, Slough, UK). He also reported that the last dental visit dated back to more than 1 year before. The clinical examination showed generalized gingival inflammation associated with poor oral hygiene.

The pulpotomy of element 35 and 37 was performed to resolve the pain. The root canal treatment were completed at subsequent appointments. The dental visit also revealed a crown loss on one dental implant (Winsix $3.8 \times 11 \mathrm{~mm}$ ) at the level of the left first molar in the mandible. The implant was placed in 2005 by a private dentist. The patient reported that he had lost the crown on the implant 1 year and a half after implant insertion and that he probably ate the crown itself. A radiographic examination was performed and revealed severe peri-implant bone loss (distal side: 6 $\mathrm{mm}$; mesial side: $6 \mathrm{~mm}$ at baseline) (Figure 1A).

The implant was considered failed because of severe bone loss, however it was stable, so the decision was taken not to remove it, in agreement with the patient desire not to perform the extraction. The patient also refused any other therapy for economical reasons. Since then, professional oral hygiene sessions were planned and performed every 6 months by a dental hygienist using carbon fiber curettes at the implant site. The patient also received detailed instructions for home dental care, but his compliance was very low.

The patient was followed-up for 2 years and bone level was evaluated over time. The health of soft and hard peri-implant tissues was controlled by periapical $\mathrm{x}$-rays and periodontal indices: plaque index (PI), bleeding on probing (BOP) and probing depth (PD) were recorded at baseline (T0), and after 6 (T6) and 12 months (T12). The radiographs were taken using a long-cone parallel technique with a film holder (Rinn bite film holder for periapical radiographs; Dentsply, York, PA, USA). Measurements of interproximal bone level were performed using as the reference point the implant platform. Bone level was assessed from this reference point to the most coronal bone-implant contact

$\mathrm{BOP}$ and $\mathrm{PD}$ were recorded using a plastic probe at 6 points around the implant: mesio-vestibular (MV), central-vestibular (CV), distal-vestibular (DV), mesio-lingual (ML), central-lingual
(CL), distal-lingual (DL). PI was recorded using a plaque detector based on erythrosine at 4 points.

After 12 months (Figure 1B), the extractions of the teeth 45, 46,47 were performed due to destructive caries. Four months after the extractions (T16) a provisional screw-retained composite crown was realized on the implant (site 36) according to the patient desire to improve mastication on the left side of the mouth. Alternative fixed and removable prosthodontic rehabilitations were proposed but the patient refused them for economical reasons. The provisional crown was $6 \mathrm{~mm}$ high (from the centre of the occlusal surface to the crown-implant connection), $12 \mathrm{~mm}$ wide from the mesial to the distal surface, and $9 \mathrm{~mm}$ wide from the vestibular to the lingual surface (Figures 1C).

Clinical and radiographic examinations were repeated two months after crown delivery (T18).

Eight months after loading, the patient came at the Department because of implant mobility, pain and suppuration at the implant level and the implant was removed (Figure 2). A careful curettage of the implant site was performed and the post-extractive site was filled up with a haemostatic reabsorbable gelatin sponge (Spongostan Dental; Johnson\&Johnson, New Brunswick, NJ, USA) without the need for suturing.

The mean values of peri-implant bone loss and periodontal indices over time are reported in Figure 3 and Table 1.

\section{Discussion}

This paper reports the effect of plaque accumulation and occlusal overload as observed on one single implant. During the entire follow-up period, the patient presented a PI and BOP of $100 \%$ at the level of the implant site. Both at T0 and T12, mean PD and mean peri-implant bone level next to the implant were $7 \mathrm{~mm}$ and $6 \mathrm{~mm}$ respectively. At T18 they were $8.6 \mathrm{~mm}$ and $7 \mathrm{~mm}$ respectively (Figure 3, Table 1). At T24 suppuration, pain and implant mobility appeared.

A localized marginal bone loss around this single implant took place. Since bone loss occurred only at this site, and not elsewhere

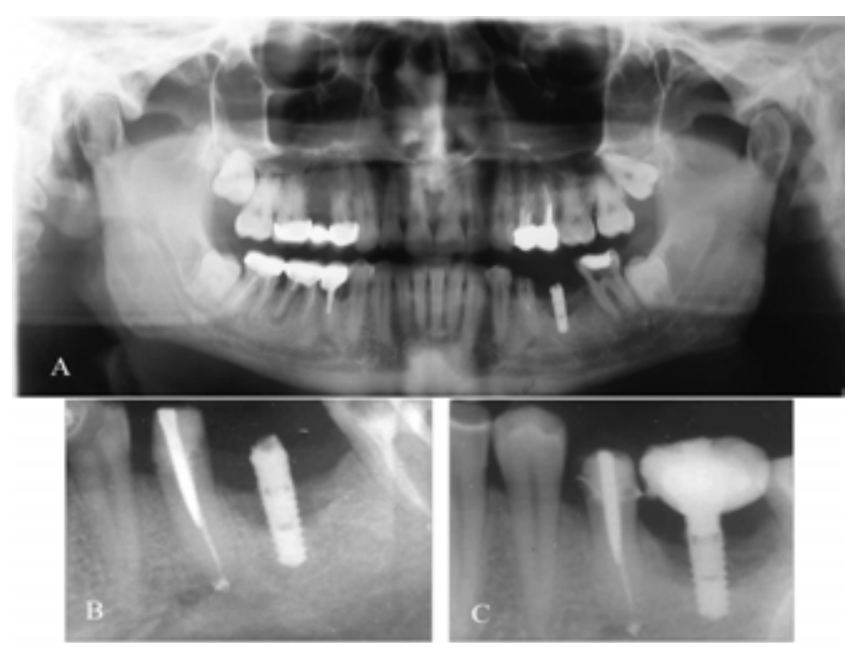

Figure 1. A) Orthopantomography performed during the first examination (T0); B) radiographic view after 6 months (T6); C) radiographic control immediately after crown delivery (T16). 
in the patient's mouth, some specific factor must have acted here. Possible factors include a variety of suppositions: microbial attack at this unique site because of the implant's particular qualities, or compromised healing of the local host site (e.g. inadequate healing following extraction; immediate placement in a damaged site; etc.), or possible contribution of a relative overload.

The implant was placed in 2005 by a private dentist and its dimensions were probably inappropriate from a biomechanical point of view given the wide vertical and mesio-distal space available. However there is no certainty about the crown-to-implant ratio $(\mathrm{C} / \mathrm{I})$ of the first rehabilitation, because the patient did not have post-surgical radiographies nor the original crown.

The provisional screw-retained crown was realized to improve mastication on the left side of the mandible in 2013. It led to a high crown-to-implant (C/I) ratio (equal to 2.4 ) due to peri-implant bone loss. Misch ${ }^{16}$ reported that a $\mathrm{C} / \mathrm{I}$ ratio of $0.5-1.0$ reduces stress on the peri-implant bone, thereby preventing bone loss and implant failure. However, $\mathrm{C} / \mathrm{I}$ ratio guidelines have not yet been established. The high $\mathrm{C} / \mathrm{I}$ ratio in the present clinical case could have influenced load transmission at peri-implant bone and induced the subsequent bone loss and implant failure. This finding is in contrast with that of other studies. ${ }^{17,18}$ The animal study by Okada et al. ${ }^{17}$ found that increased C/I may not be a risk factor for implant failure if the periimplant mucosa is kept healthy. The clinical study by Tawil et al. ${ }^{18}$ focused on 262 short $(<10 \mathrm{~mm})$ machined-surface implants consecutively placed in 109 patients and increased C/I values did not seem to be a major risk factor for peri-implant bone loss and implant failure at the medium-term follow-up.

In the present case report the crown was realized in composite resin, a material that appeared to be able to absorb shock from occlusal forces when compared with crowns made of zirconia, ceramic material, or gold alloy. ${ }^{19}$ This choice was made in the attempt to reduce the load on the implant. Even though the intensity, frequency and duration of the occlusal overload could not be measured, the implant was considered overloaded because the patient chew only with the left side of his mouth, as the elements 45, 46, 47 had been extracted.

Severe peri-implant bone loss occurred before the patient came for a dental examination at the Prosthodontics Department. Probably bone resorption took place when the original crown was present and the implant was in function under occlusal load. Then peri-implant bone level remained stable as long as the implant was not loaded, although a $100 \%$ PI was present. In contrast, as soon as an occlusal load was applied peri-implant bone loss and implant failure occurred.

In successfully osteointegrated implants, the microflora identified is dominated by Streptococcus species such as $S$. intermedius,
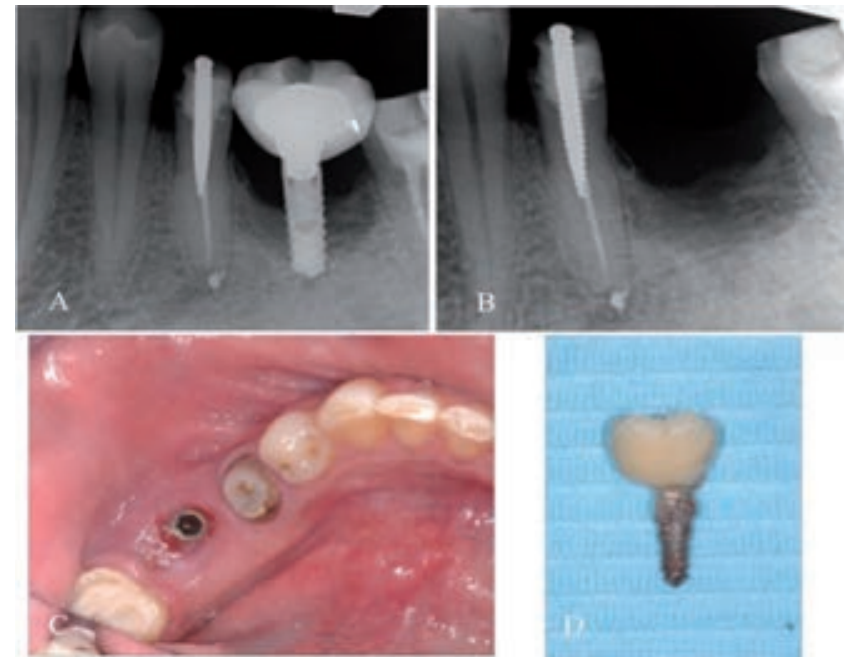

Figure 2 A) Radiographic control after 8 months of loading (T24); B) radiographic control of the post-extractive site; C) occlusal view immediately before implant extraction; D) dental implant extracted.

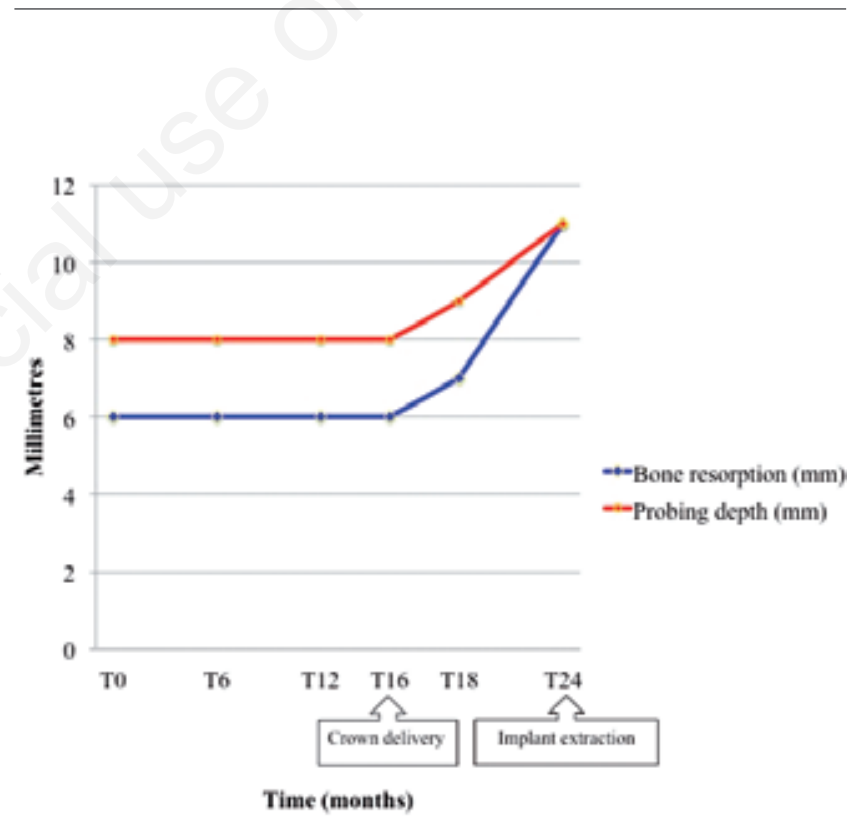

Figure 3. Time trend of probing depth and bone resorption during the 2-year follow-up (mean values).

Table 1. Values of peri-implant bone loss, probing depth, bleeding on probing and plaque index during the entire follow-up.

\begin{tabular}{|c|c|c|c|c|c|c|}
\hline & \multicolumn{2}{|c|}{ Peri-implant bone loss (mm) } & \multicolumn{2}{|c|}{ PD (mm) } & \multirow[t]{2}{*}{ BOP $(\%)$} & \multirow[t]{2}{*}{ PI $(\%)$} \\
\hline & Mesial site & Distal site & Mesial site & Distal site & & \\
\hline T0 & 6 & 6 & 7.5 & 8.5 & 100 & 100 \\
\hline T6 & 6 & 6 & 7.5 & 8.5 & 100 & 100 \\
\hline $\mathrm{T} 12$ & 6 & 6 & 7.5 & 8.5 & 100 & 100 \\
\hline T16 & 6 & 6 & 7.5 & 8.5 & 100 & 100 \\
\hline $\mathrm{T} 18$ & 7 & 7 & 9 & 9 & 100 & 100 \\
\hline $\mathrm{T} 24$ & 11 & 11 & 11 & 11 & 100 & 100 \\
\hline
\end{tabular}

PD, probing depth; BOP, bleeding on probing; PI, plaque index; T0, baseline; T6, after 6 months; T12, after 12 months; T16, after 16 months; T18, after 18 months; $T 24$, after 24 months. 
S. oralis, S. Sanguinis, S. gordonii, V. parvula, F. Nucleatum and Capnocytophaga gingivalis. ${ }^{20}$ However, conflicting data regarding the microbial species involved in the formation of the biofilms on the surface of implants and tooth during the initial phases of biofilm formation have been published, as either similar ${ }^{21}$ or distinct patterns ${ }^{22}$ have been observed. With regard to this aspect, it has been highlighted that the dental status significantly impacts microbial colonization of implant surfaces, as in partially edentuolous patients, microorganisms from the subgingival areas of teeth may invade implant sites and lead to colonization of implant surfaces, suggesting that in edentulous patients without any subgingival reservoir no transition of periodontal pathogens occurs. ${ }^{23}$

Gram-negative bacteria can be found in smaller proportions in healthy peri-implant sites and include Prevotella intermedia,
Porphyromonas gingivalis, Tannerella forsythia, Prevotella nigrescens, and Campylobacter rectus. ${ }^{20}$ As the peri-implant tissues undergo the process from a state of health to that of disease, a shift from a Gram-positive facultative dominated flora to a Gramnegative anaerobic biofilm occurs. ${ }^{24}$ The failing implant is characterized by a greater proportion of red ( $P$. gingivalis, Treponema denticola, and $T$. forsythia) and orange ( $P$. intermedia and Fusobacterium nucleatum) complex, as well as Aggregatibacter actinomycetemcomitans and Eikenella corrodens with a lower proportion of the flora associated with health. ${ }^{25}$ Hence, the main differences between health and disease are in the proportions of Actinomyces, orange and red complex species. Furthermore, increasing peri-implant probing depth has been significantly associated with higher total anaerobic cultivable microbiota and the

Table 2. Microbiota associated with dental implants. ${ }^{20,25,26}$

\begin{tabular}{|c|c|}
\hline & Gram-positive bacteria Gram-negative bacteria \\
\hline Subgingival plaque associated with implants & $\begin{array}{c}\text { S. sanguis } \\
\text { H. actinomycetemcomitans } \\
\text { Copnocytophago spp. } \\
\text { E. corrodens } \\
\text { F. nucleatum } \\
\text { Bacteroides spp. } \\
\text { C. sputorum } \\
\text { V. parvula } \\
\text { L. buccalis } \\
- \\
- \\
-\end{array}$ \\
\hline Supragingival plaque associated with implants & $\begin{array}{c}\text { HS } \\
\text { HS } \\
\text { H. actinomycetemcomitans } \\
\text { Copnocytophago spp. } \\
\text { E. corrodens } \\
\text { F. nucleatum } \\
\text { Bacteroides spp. } \\
\text { L. buccalis } \\
\text { V. parvula } \\
- \\
- \\
-\end{array}$ \\
\hline Microbiota of failing implants & $\begin{array}{c}\text { Prevotella intermedia } \\
\text { P. nigrescens } \\
\text { A. actinomycetemcomitans } \\
\text { Staphylococci, coliforms, candida spp. } \\
\text { Bacteroides forsythus } \\
\text { Spirochetes } \\
\text { Fusobacterium spp. } \\
\text { Porphyromonas gingivalis } \\
\text { Bacteroides spp. } \\
\text { Fusiform bacilli, motile and curve rods } \\
\text { Staphylococcus spp. } \\
\text { P. nicrescens, P. micros } \\
\text { Fusobacterium nucleatum } \\
\text { Capnocytophaga spp } \\
\text { Eikenella corrodens } \\
\text { Campylobacter rectus } \\
\text { Treponema denticola } \\
\text { Tannerella forsythia } \\
\text { Enterococcus spp. } \\
\text { Yeast spp. }\end{array}$ \\
\hline
\end{tabular}


frequency of detection of $P$. gingivalis. ${ }^{26}$ Table 2 shows microbiota around dental implants.

The observations of this case report suggest that plaque accumulation alone is not a triggering factor for peri-implant bone loss and implant failure. On the contrary, occlusal load, when not properly controlled, might cause bone resorption. This might be exacerbated by microbial insult.

After osseointegration is obtained, a direct and relatively rigid connection between bone and the implant surface is achieved. ${ }^{27}$ In these conditions, the peri-implant bone architecture develops an adaptation capacity to change in response to load conditions. According to Frost ${ }^{28}$ within the range of a physiological loading, bone undergoes its physiological turn-over. In mild overloading, modelling drifts can begin adding to and/or reshaping bone, but in the case of a pathologic overload bone fractures and bone resorption may occur ${ }^{28}$. However, the amount of load to be defined as overload has not been quantified, also because the range of host physiological adaptability varies. ${ }^{19}$

Up to now, clinical evidence on the impact of overloading on peri-implant bone is not available. The inability to quantitatively define overloading, as well as several methodological and ethical limitations, has seriously compromised the potential of human studies to draw valid conclusions.

On the other hand, data on animal studies should be used with caution when discussing clinical evidence: dental implants are exposed to a complex series of different phenomena (both chemical and physical) in human and animal oral cavities including diet, oral hygiene, occlusal function, etc.

\section{Conclusions}

In conclusion, the present case report suggests that occlusal loading plays an important role in bone resorption and implant failure. However, data from case reports must be interpreted with caution without any generalization. Well designed clinical trials based on a greater number of patients are needed to validate the present outcomes.

\section{References}

1. Pesce P, Menini M, Tealdo T, et al. Peri-implantitis: a systematic review of recently published papers. Int $\mathrm{J}$ Prosthodont 2014;:27:15-25.

2. Han HJ, Kim S, Han DH. Multifactorial evaluation of implant failure: a 19-year retrospective study. Int J Oral Maxillofac Implants 2014;29:303-10.

3. Kozlovsky A, Tal H, Laufer BZ, et al. Impact of implant overloading on the peri-implant bone in inflamed and non-inflamed peri-implant mucosa. Clin Oral Implants Res 2007;18:601-10.

4. Miyata T, Kobayashi Y, Araki H, et al. The influence of controlled occlusal overload on peri-implant tissue. Part 3: a histologic study in monkeys. Int $\mathrm{J}$ Oral Maxillofac Implants 2000;15:425-31.

5. Wennerberg A, Albrektsson T. On implant surfaces: a review of current knowledge and opinions. Int $\mathrm{J}$ Oral Maxillofac Implants 2010;25:63-74.

6. Marotti G. The osteocyte as a wiring transmission system. J Musculoskel Neuron Interact 2000;1:133-6.

7. Duyck J, Rønold HJ, Van Oosterwyck H, et al. The influence of static and dynamic loading on marginal bone reactions around osseointegrated implants: an animal experimental study. Clin Oral Implants Res 2001;12:207-18.

8. Isidor F. Influence of forces on peri-implant bone. Clin Oral Implants Res 2006;17(Suppl 2):8-18.

9. Nagasawa M, Takano R, Maeda T, Uoshima K. Observation of the bone surrounding an overloaded implant in a novel rat model. Int J Oral Maxillofac Implants 2013;28:109-16.

10. Naert I, Duyck J, Vandamme K. Occlusal overload and bone/implant loss. Clin Oral Implants Res 2012;23:S95-S107.

11. Fu JH, Hsu YT, Wang HL. Identifying occlusal overload and how to deal with it to avoid marginal bone loss around implants. Eur J Oral Implantol 2012;5:91-103.

12. Lobbezoo F, Van Der Zaag J, Naeije M. Bruxism: its multiple causes and its effects on dental implants - an updated review. J Oral Rehab 2006;33:293-300.

13. Mattheos N, Schittek Janda M, Zampelis A, Chronopoulos V. Reversible, non-plaque-induced loss of osseointegration of successfully loaded dental implants. Clin Oral Implants Res 2013;24:347-54.

14. Costa FO, Takenaka-Martinez S, Cota LOM, et al. Peri-implant disease in subjects with and without preventive maintenance: a 5-year follow-up. J Clin Periodontol 2012;39:173-81.

15. Baldi D, Menini M, Pera F, et al. Plaque accumulation on exposed titanium surfaces and peri-implant tissue behavior. A preliminary 1-year clinical study. Int J Prosthodont 2009;22: 447-55.

16. Misch CE. Progressive loading of bone with implant prostheses. J Dent Symp 1993;1:50-3.

17. Okada S, Koretake K, Miyamoto Y, et al. Increased crown-toimplant ratio may not be a risk factor for dental implant failure under appropriate plaque control. PLoS One 2013;30:8:e63992.

18. Tawil G, Aboujaoude N, Younan R. Influence of prosthetic parameters on the survival and complication rates of short implants. Int J Oral Maxillofac Implants 2006;21:275-82.

19. Menini M, Conserva E, Tealdo T, et al. Shock absorption capacity of restorative materials for dental implant prostheses: an in vitro study. Int J of Prosthodontics 2013;26:549-56.

20. Lee KH, Maiden MF, Tanner AC, Weber HP. Microbiota of successful osseointegrated dental implants. J Periodontol 1999;70: 131-8.

21. Quirynen M, Vogels R, Peeters W, et al. Dynamics of initial subgingival colonization of 'pristine' peri-implant pockets. Clin Oral Implants Res 2006;17:25-37.

22. Fürst MM, Salvi GE, Lang NP, Persson GR. Bacterial colonization immediately after installation on oral titanium implants. Clin Oral Implants Res 2007;18:501-8.

23. Deng Y, Lw V. Biofilm and implantable medical devices: infection and control. Cambridge: Elsevier Ltd; 2017. pp. 122-5.

24. Mombelli A, van Oosten MA, Schurch E Jr, et al. The microbiota associated with successful or failing osseointegrated titanium implants. Oral Microbiol Immunol 1987;2:145-51.

25. Shibli JA, Melo L, Ferrari DS, et al. Composition of supra- and subgingival biofilm of subjects with healthy and diseased implants. Clin Oral Implants Res 2008;19:975-82.

26. Rutar A, Lang NP, Buser D, et al. Retrospective assessment of clinical and microbiological factors affecting periimplant tissue conditions. Clin Oral Implants Res 2001;12:189-95.

27. Skalak R. Biomechanical considerations in osseointegrated prostheses. J Prosthet Dent 1983;49:843-8.

28. Frost HM. Wolff's law and bone's structural adaptations to mechanical usage: an overview for clinicians. Angle Orthod 1994;64:175-88. 